\title{
Integrating microRNA and mRNA expression profiles of neuronal progenitors to identify regulatory networks underlying the onset of cortical neurogenesis \\ Joseph A Nielsen* ${ }^{* 1,2}$, Pierre Lau ${ }^{\dagger 1}$, Dragan Maric ${ }^{3}$, Jeffery L Barker ${ }^{3}$ and Lynn D Hudson ${ }^{1}$
}

Address: ${ }^{1}$ Section of Developmental Genetics, National Institute of Neurological Disorders and Stroke, National Institutes of Health, Bethesda, Maryland, USA, ${ }^{2}$ Center for Devices and Radiological Health, Food and Drug Administration, Silver Spring, Maryland, USA and ${ }^{3}$ Laboratory of Neurophysiology, National Institute of Neurological Disorders and Stroke, National Institutes of Health, Bethesda, Maryland, USA

Email: Joseph A Nielsen* - joseph.nielsen@fda.hhs.gov; Pierre Lau - laup@ninds.nih.gov; Dragan Maric - maricd@ninds.nih.gov; Jeffery L Barker - jeffery.barker@nih.hhs.gov; Lynn D Hudson - hudsonl1@od.nih.gov

* Corresponding author †Equal contributors

Published: 19 August 2009

BMC Neuroscience 2009, 10:98 doi:10.1 186/147|-2202-10-98
Received: 2 December 2008

Accepted: 19 August 2009

This article is available from: http://www.biomedcentral.com//47/-2202/10/98

(c) 2009 Nielsen et al; licensee BioMed Central Ltd.

This is an Open Access article distributed under the terms of the Creative Commons Attribution License (http://creativecommons.org/licenses/by/2.0), which permits unrestricted use, distribution, and reproduction in any medium, provided the original work is properly cited.

\begin{abstract}
Background: Cortical development is a complex process that includes sequential generation of neuronal progenitors, which proliferate and migrate to form the stratified layers of the developing cortex. To identify the individual microRNAs (miRNAs) and mRNAs that may regulate the genetic network guiding the earliest phase of cortical development, the expression profiles of rat neuronal progenitors obtained at embryonic day II (EII), EI 2 and EI 3 were analyzed.

Results: Neuronal progenitors were purified from telencephalic dissociates by a positive-selection strategy featuring surface labeling with tetanus-toxin and cholera-toxin followed by fluorescenceactivated cell sorting. Microarray analyses revealed the fractions of miRNAs and mRNAs that were up-regulated or down-regulated in these neuronal progenitors at the beginning of cortical development. Nearly half of the dynamically expressed miRNAs were negatively correlated with the expression of their predicted target mRNAs.

Conclusion: These data support a regulatory role for miRNAs during the transition from neuronal progenitors into the earliest differentiating cortical neurons. In addition, by supplying a robust data set in which miRNA and mRNA profiles originate from the same purified cell type, this empirical study may facilitate the development of new algorithms to integrate various "-omics" data sets.
\end{abstract}

\section{Background}

Neurogenesis commences in the developing telencephalon when symmetrically dividing neural stem cells in the neuroepithelium begin to divide asymmetrically $[1,2]$. Neuronal progenitors proliferate and migrate to form the stratified layers of the cortex, with the earliest neurons forming the preplate or primordial plexiform layer $[3,4]$. A number of genes that are required for the proper formation of the cortex have already been identified including the transcription factors Pax6 and FoxG1 $[5,6]$. Larger scale genomic approaches have also been used to identify genes important for cortical development, 
and these studies have added to the catalog of genes that may be required during cortical neurogenesis $[7,8]$.

Other participants in gene regulatory networks include microRNAs (miRNAs), which are short non-coding RNA molecules that bind to target mRNAs and cause either RNA degradation or translation inhibition (reviewed in $[9,10])$. miRNAs were originally identified in the regulation of a developmental transition in C. elegans [11]. miRNAs are expressed in all tissues, but the brain appears to have the highest diversity of miRNA expression [12]. A number of brain-enriched miRNAs have been identified including miR-9 and miR-124a [12-14]. These two miRNAs have been shown to play a role in promoting the transition from neuronal progenitors into differentiated neurons $[15,16]$. Several reports have identified inverse expression patterns between a miRNA and predicted targets, including brain-enriched miRNAs $[17,18]$. Despite this progress, there remains a large gap in our understanding of how the different miRNAs expressed during brain development regulate cortical neurogenesis.

A major limitation in the network analysis of genetic circuits is the availability of mRNA and miRNA profiles from the same cell type. Most of the transcriptome and microRNAome data derive from separate studies, typically drawn from examining whole tissues instead of individual cell types, and are often taken at different developmental time points. The present study overcomes these limitations and provides a robust data set for developing new algorithms to detect modulation of target gene expression by miRNAs. Our objective was to identify miRNA and mRNA expression patterns that may contribute to the earliest stages of neurogenesis. By obtaining expression-profiling data from highly purified neuronal progenitors, we were able to analyze the dynamic global changes in miRNA and mRNA expression that occur at the onset of neurogenesis. The use of fluorescence-activated cell sorting (FACS) and a positive-selection strategy provided the cell purity required for the analysis of neuronal cell populations from a complex tissue, reducing the ambiguity that can be introduced by contaminating cell populations, and eliminated the pitfalls of cell lines and cultured primary cells.

Here we provide evidence that a subset of miRNAs exhibits expression profiles that are negatively correlated with their predicted target mRNAs, and therefore may be part of a gene expression regulatory network that assists in the transition from proliferating neuronal progenitor cells into differentiated neuronal subtypes. In addition, this study identifies a number of candidate transcription factors (TFs) that are expressed in the developing telencephalon and may be important in initiating cortical neurogenesis.

\section{Results \\ FACS isolation of neuronal progenitors from the developing telencephalon}

We focused on the earliest neuronal progenitors in the rat telencephalon that co-express tetanus toxin and cholera toxin $\left(\mathrm{TnTx}^{+} / \mathrm{ChTx}^{+}\right)$-binding gangliosides on their surface membrane, but lack the expression of the neuronal progenitor markers A2B5 and Jones (CDw60), which label a separate pool of progenitors that also generate neurons and later, glial phenotypes. $\mathrm{TnTx}^{+} / \mathrm{ChTx}^{+} / \mathrm{A} 2 \mathrm{~B} 5-/$ Jones- cells represented $5.1 \%$ of the total number of cells in the rat telencephalon at embryonic day 11 (E11), 8.9\% at E12, and $27.8 \%$ at E13. We have previously defined these $\mathrm{TnTx}^{+} / \mathrm{ChTx}^{+} / \mathrm{A} 2 \mathrm{~B} 5-/$ Jones $^{-}$cells as early neuronal progenitors (ENPs) [19]. There were not enough ENPs present at E10, but by E11 these cells could be isolated in sufficient numbers to obtain total RNA for microarray analysis (Figure 1A). At E13, there were enough cells to split the $\mathrm{TnTx}^{+} / \mathrm{ChTx}^{+} / \mathrm{A} 2 \mathrm{~B} 5$-/Jones- cells into approximately equal low and high expressing populations, with the latter being defined as late neuronal progenitors (LNPs), based on their later ontogenetic appearance at E13 and progressive accumulation of these cells during late stages of cortical neurogenesis [20]. The positivelyselected ENPs and LNPs cells were sorted directly into RNAlater to preserve RNA integrity. The quality of the total RNA isolated with this method was confirmed by the presence of intact ribosomal RNA bands (Figure 1B). After hybridization, the microarray dataset was assessed using principle component analysis. The independent biological replicates clustered together by embryonic days of development (Figure 1C). There was little difference in the expression profiles of ENPs and LNPs at E13, as these two populations did not resolve into separate groups. Correlation analysis was performed on each group of biological replicates (Figure 1D). The correlation coefficient was greater than 0.94 for the biological replicates at each of the developmental time points, demonstrating a high level of reproducibility among independently obtained replicates.

To provide spatial information on the neuronal progenitor cell population in the developing telencephalon, sagittal sections of E12 rat ventral telencephalon were immunostained with anti-nestin, anti-PCNA, antiCDw60/Jones and anti-beta-tubulin III/Tuj1. Tuj1 (a panneuronal cytoskeletal marker) was used in place of TnTx (a pan-neuronal surface marker) to provide better visualization of neuronal cell bodies in the section. Four different cell phenotypes were identified using this method (Figure 2). The Jones- $/ \mathrm{TnTx}^{+}$neuronal progenitors isolated by FACS for microarray analysis at E12 in this study are represented by Jones-/Tuj $1^{+}$cells (population $b$ in Figure 2, panels $3 \mathrm{C}$ and $3 \mathrm{D}$ ), which are predominately located near the pial surface of the ventral telencephalon. 

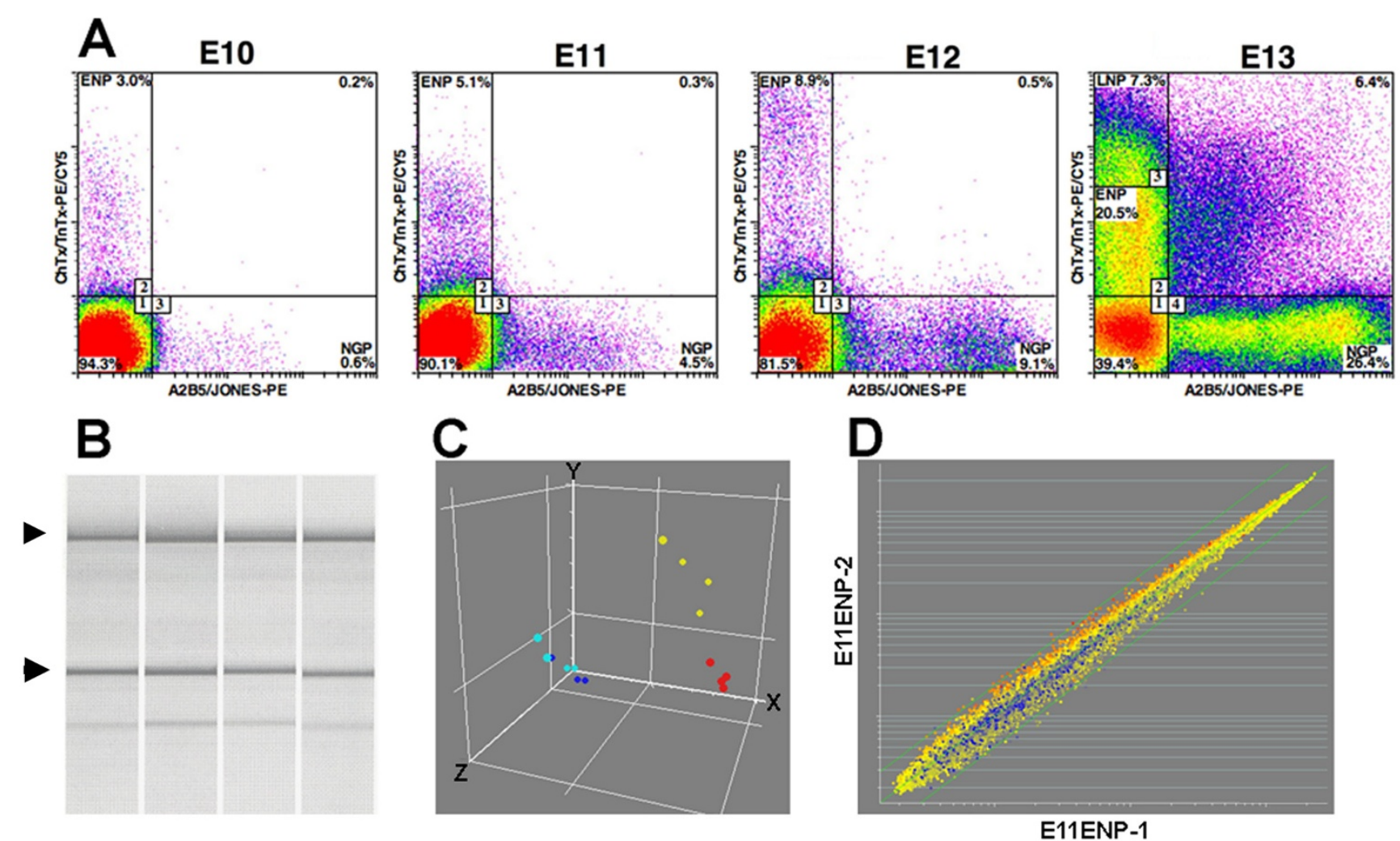

\section{Figure I}

Neuronal progenitors can be purified directly from the rat telencephalon using flow cytometry. Dissociates were labeled using the pan-neuronal markers TnTx and ChTx in addition to A2B5 and Jones, which identify a separate lineage that also includes neuronal progenitors and later neuroglial progenitors (NGP). A. Bivariate FACS plots reveal a developmental increase in $\mathrm{TnTx}^{+} / \mathrm{ChTx}^{+} / \mathrm{A} 2 \mathrm{~B} 5-/ /$ ones- early neuronal progenitors (ENP) from $3 \%$ to $20.5 \%$ and the emergence of late neuronal progenitors (LNP) at EI3. $\mathrm{TnTx}^{+} / \mathrm{ChTx}^{+}$immunofluorescence signals were used to sort-purify populations of viable cells at embryonic days EII, EI2 and EI3. Sorting gates were set to collect TnTx+/ChTx+/A2B5-/Jones-ENPs and, at EI3, LNPs, which were identified on the basis of relative fluorescence intensities of $T n T x$ and ChTx staining reactions (upper left quadrant). B. Analysis of total RNA extracted from NPs isolated by FACS shows the presence of intact I8S and 28S rRNA bands (arrow heads). C. Principle component analysis demonstrates the reproducibility of the biological replicates. Red circles = EI I ENPs; yellow circles = EI 2 ENPs; light blue circles = EI 3 ENPs; dark blue circles = EI 3 LNPs. D. Scatter plot of two EI I ENP biological replicates. Correlation analysis was performed on the biological replicates within each group. The correlation coefficient was greater than 0.94 for each replicate.

\section{mRNAs and miRNAs are dynamically regulated during neurogenesis}

Clustering analysis was used to identify the prevalent gene expression patterns in the data sets. In the mRNA microarray experiment, there was little change in the expression level of the vast majority of mRNAs represented by the 31,099 probe sets on the Affymetrix microarrays during the developmental period surveyed. Only $7.2 \%$ of the probe sets underwent significant changes between E11 to E13. The gene lists were obtained using a combination of a statistical filter and a 2-fold change in normalized expression value (see Methods section). There were two dominant gene expression patterns for these mRNAs. One class of mRNAs was down-regulated as development progressed from E11 to E13 (Figure 3A), while another class of mRNAs was up-regulated during this time frame (Figure $3 \mathrm{~B}$ ). A parallel result came from the clustering analysis of differentially-regulated miRNAs. One class of miRNAs was down-regulated and another class up-regulated between E11 and E13 (Figure 3C, D). There were 21 miRNAs down-regulated and 11 miRNAs up-regulated between E11 and E13 (Table 1). Among the miRNAs iden- 

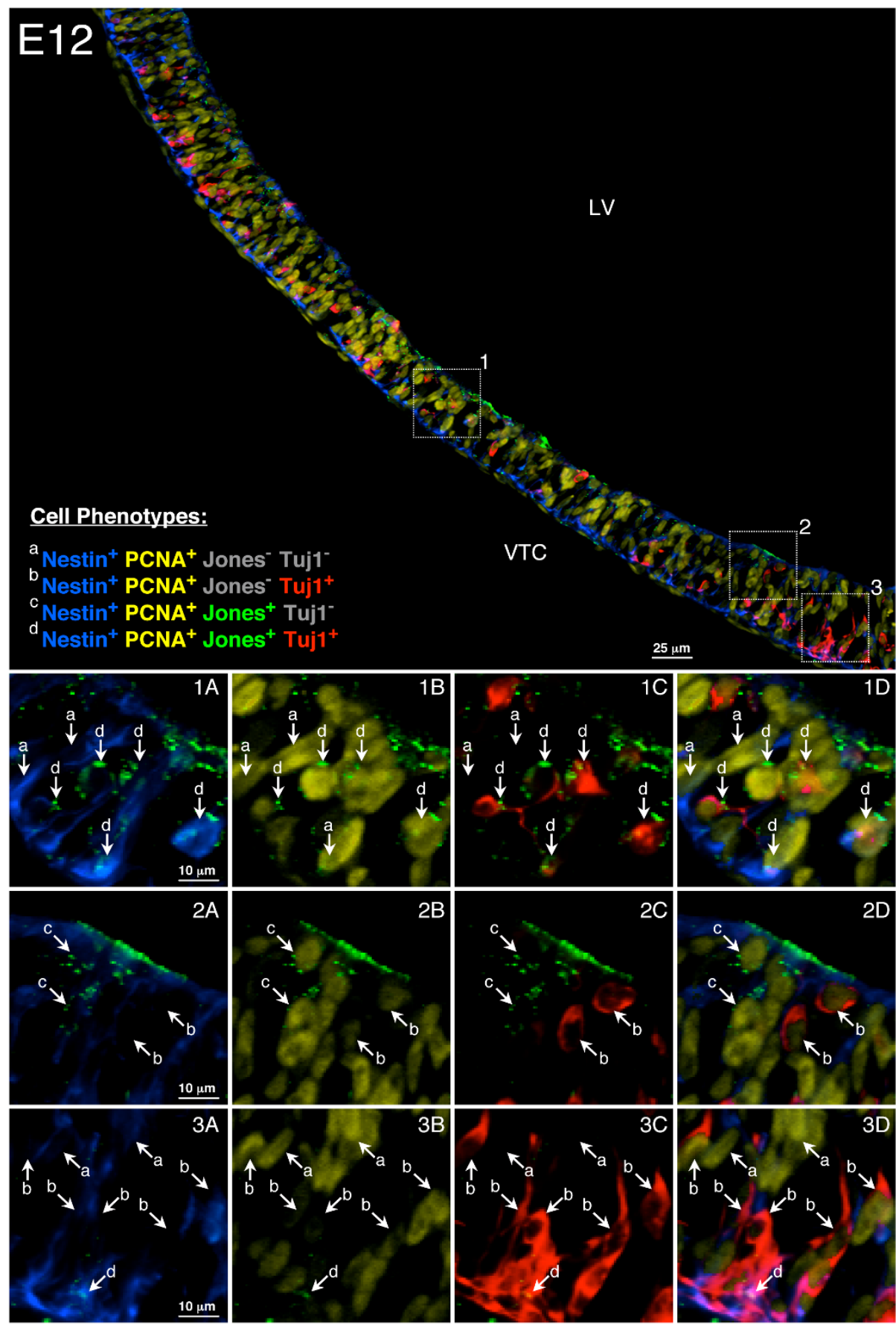

Figure 2

Neuronal progenitors are located in the ventral telencephalon near the pial surface. Sagittal sections of EI 2 rat ventral telencephalon were immunostained with anti-nestin (blue), anti-PCNA (yellow), anti-CDw60/Jones (green) and antibeta-tubulin III/TujI (red). Tuj I antibody was used in place of TnTx to provide a better visualization of neuronal cell bodies. Insets I-3 in the top panel are enlarged in the bottom panels (IA-D, 2A-D, 3A-D) to show the anatomical distribution of the 4 major neural phenotypes, which were classified as follows: (a) Nestin+PCNA+Jones-Tuj I- neural stem/precursor cells, (b) Nes$\operatorname{tin}^{+} \mathrm{PCNA}^{+} \mathrm{J}^{+} \mathrm{s}^{-} \mathrm{Tuj} \mathrm{I}^{+}$neuronal progenitors and post-mitotic neurons, which are predominantly Nestin-PCNA-, (c) Nes-

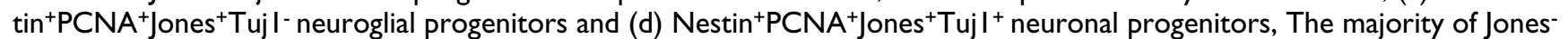
$\mathrm{TnTx}^{+}$neuronal progenitors isolated by FACS for microarray analysis in this study are represented by Jones-Tuj ${ }^{+}$cells (population b) located near the pial surface as shown in panels $3 C$ and $3 D$. 
Table I: Differentially regulated miRNAs identified in neuronal progenitors between $\mathrm{EI} I$ and EI 3 using microarray analysis.

\begin{tabular}{lclc}
\hline Down-regulated & Fold $\Delta$ & Up-regulated & Fold $\Delta$ \\
\hline miR-292-3p & 19.2 & miR-9 & 144.3 \\
miR-126 & 17.1 & miR-125b & 30.3 \\
miR-200c & 6.8 & miR-125a & 12.7 \\
miR-20b* & 6.6 & miR-18Ib & 12.4 \\
miR-29I-3p & 6.0 & miR-99a & 10.3 \\
miR-20b & 5.5 & miR-100 & 7.2 \\
miR-363-3p & 5.2 & miR-99b & 7.2 \\
miR-199a & 4.4 & miR-18Ic & 7.2 \\
miR-145 & 4.4 & miR-218 & 4.6 \\
miR-183 & 4.2 & miR-7 & 4.1 \\
miR-143 & 4.2 & miR-124a & 2.6 \\
miR-92 & 4.2 & & \\
miR-200b & 3.9 & & \\
miR-19a & 3.5 & & \\
miR-222 & 3.3 & & \\
miR-205 & 3.2 & & \\
miR-18 & 3.1 & & \\
miR-219 & 2.9 & & \\
miR-210 & 2.8 & & \\
miR-214 & 2.6 & & \\
miR-290 & 2.6 & & \\
\hline
\end{tabular}

tified as up-regulated, there were several that have previously been found to be expressed in neuronal progenitors, including miR-9 and miR-124a. As was the case for mRNAs, the majority of miRNAs did not change expression patterns from E11 to E13.

Before proceeding with a bioinformatic analysis of the datasets, microarray validation was performed using quantitative reverse transcription-PCR (qRT-PCR) and immunohistochemistry. qRT-PCR was first used to validate miRNA expression, and the data confirmed the expression of each of the 11 miRNAs identified in E13 ENPs (Table 1, see additional file 1). To validate the mRNA microarray data, qRT-PCR was used to detect 7 TFs that were up-regulated in ENPs between E11 and E13, including onecut, Cutl1, Myt1, Klf7, Lhx1, Bcl11a and $B c l 11 b$ (Figure 4A, B). The qRT-PCR results agreed with the microarray data for each of the 7 TFs tested. The magnitude of the fold-changes differed, but this likely reflects the difficulty in reproducibly detecting low expression levels of transcripts at E11. An antibody directed against the Cutl1 protein was used to confirm the protein expression of one of the TFs identified by microarray analysis. Cutl 1 protein expression was detected in the ventral and dorsal telencephalon consistent with the 3.0-fold increase in Cutl1 mRNA expression in E13 ENPs (Figure 4B, C, D). Additional validation was obtained using the Mahoney transcription factor in situ hybridization database [21]. In total, sixty TFs were identified as up-regulated in E13 ENPs (Table 2). Of those $60 \mathrm{TFs}, 30$ were found in the Mahoney database at mouse E13, which is approximately 1.5 days earlier than the rat E13 time-point used in this study. Notably, 16 of $30(53 \%)$ displayed a positive in situ hybridization signal in the mouse telencephalon.

After validation of the microarray dataset, gene ontology (GO) analysis was performed to identify the classes of genes that were being differentially regulated in ENPs between E11 and E13. The 15 biological process GO categories with the most mRNAs in both the down-regulated class (Figure 5A), and the up-regulated class (Figure 5B) are detailed in Figure 5. The most striking finding was the number of mRNAs encoding TFs that were identified in both categories of differentially regulated genes (Table 2 and see additional file 2). Also of note was the number of cell cycle genes that were being down-regulated (see additional file 3 ), and the large number of up-regulated transcripts encoding proteins important for neuronal differentiation (Table 3 ).

\section{miRNA expression is negatively correlated with predicted target mRNA expression}

In addition to the identification of genes that may be important during neurogenesis, the mRNA and miRNA datasets were compared to determine whether there was evidence of differential expression of miRNAs influencing mRNA expression during the onset of cortical neurogenesis. The predicted targets for each of the miRNAs that were differentially regulated were compiled using TargetScan 4.0. The predicted mRNA targets were compared to the experimentally-determined, differentially-regulated mRNAs to identify the number of predicted mRNA targets that actually changed expression levels between E11 and E13. A two-tailed Fisher's Exact Test was used to determine whether the number of target mRNAs that changed expression was greater than would be expected by chance. The results of this analysis are presented in Figure 6. When testing miRNAs that were down-regulated, 7 of $21 \mathrm{miR}-$ NAs (33\%) had a significant number of target mRNAs that were up-regulated. miR-199a had significantly less target mRNAs up-regulated than would be expected by chance, and was not counted as having an inverse expression pattern. When testing miRNAs that were up-regulated, 7 of 11 miRNAs (64\%) had a significant number of mRNA targets that were down-regulated.

GO analysis was performed on the list of predicted target mRNAs that were in common with mRNAs that were differentially regulated between E11 and E13. This analysis compared the mRNAs that were predicted to be targeted by miRNAs with those mRNAs that were experimentally determined to change expression levels. Cell migration was the top GO category of down-regulated mRNAs predicted to be targeted by up-regulated miRNAs. Moreover, genes regulating neuron differentiation was the top GO 

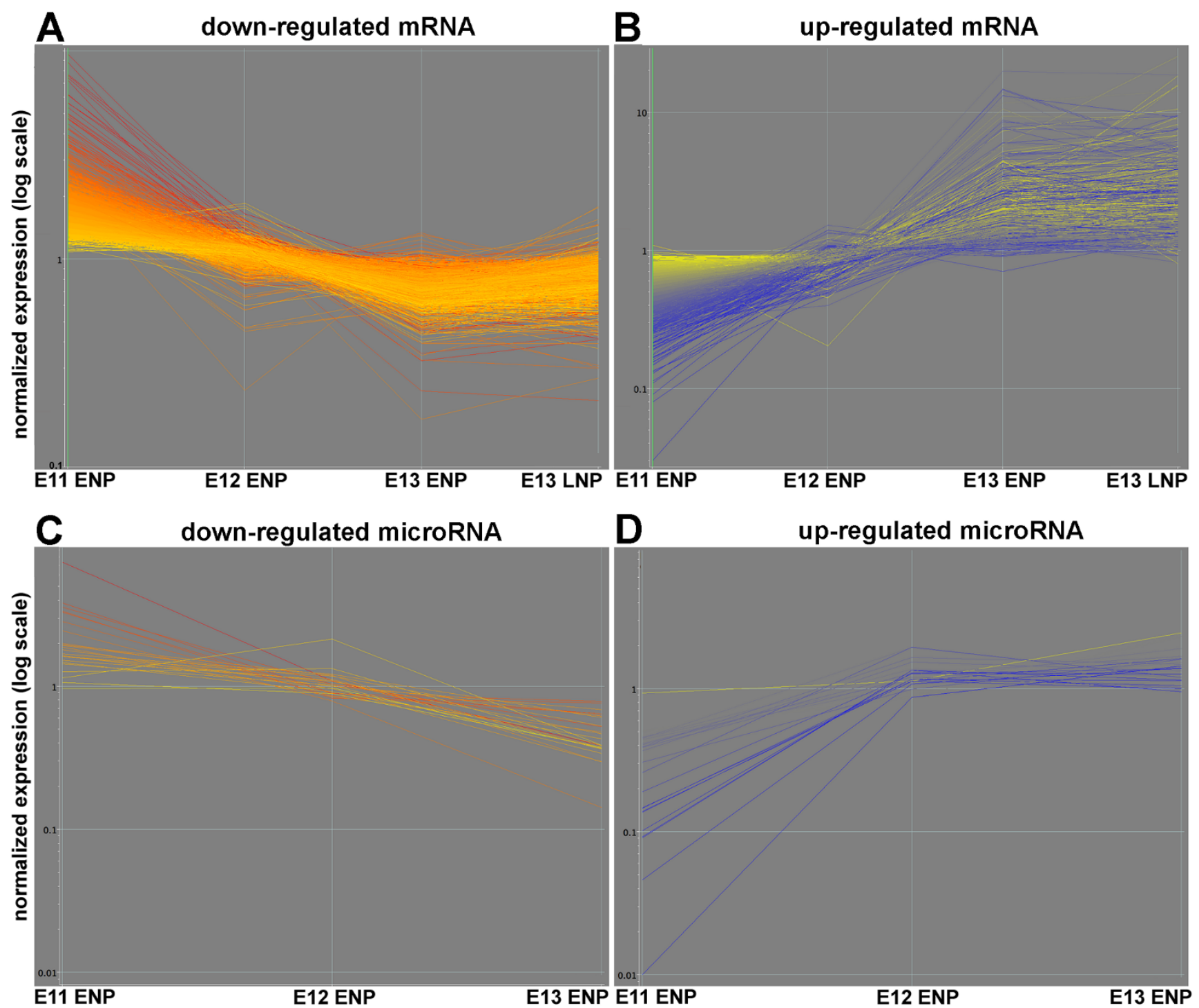

\section{Figure 3}

mRNAs and miRNAs are dynamically regulated during the onset of cortical neurogenesis. K-means clustering analysis was applied to the normalized expression data (see Materials and Methods). Two major classes of differentially regulated mRNAs (A, B) and miRNAs (C, D) were identified. The mRNA and miRNA expression levels were colored by the relative expression levels in EI I ENPs with red being the highest and blue being the lowest globally normalized expression level.

category of up-regulated mRNAs predicted to be targeted by down-regulated miRNAs (Figure 7).

Network analysis was performed to determine whether different miRNAs were predicted to interact with common target mRNAs encoding TFs. We used TargetScan 4.0 to predict miRNA binding sites in the 3 ' untranslated region (3'UTR) of the 60 up-regulated TFs in E13 ENPs. There were 74 predicted miRNA binding sites for miRNAs that were down-regulated. There were 55 miRNA predicted binding sites for miRNAs that were up-regulated. Focusing on the down-regulated miRNAs that had a significant negative correlation in Figure 6, we performed network analysis and identified miR-92, miR-183, miR-222 and miR291-3p as predicted to target multiple TFs that were upregulated in E13 ENPs (Figure 8).

\section{Discussion}

Neurogenesis is an extraordinarily complex process that is just beginning to be understood at the molecular level. In this study, we sought to identify genes that are important in regulating the onset of cortical neurogenesis, and to 
Table 2: 60 mRNAs encoding transcription factors are up-regulated in neuronal progenitors between EII and EI3.

\begin{tabular}{|c|c|c|c|c|}
\hline Affymetrix ID & Fold $\Delta$ & GenBank & Gene & Gene Description \\
\hline 1379530_at & 48.3 & AA964658 & & Eomesodermin \\
\hline 1392064_at & 30.2 & BF400590 & Dlx & distal-less homeobox I (predicted) \\
\hline 1383010_at & 19.1 & AW531880 & & B-cell CLL/lymphoma IIA (zinc finger protein) (predicted) \\
\hline |377|7|_at & 10.9 & AA87504I & Lzts I & leucine zipper, putative tumor suppressor I \\
\hline 1391948_at & 9.8 & $\underline{B M 390227}$ & $\mathrm{Bclllb}$ & B-cell leukemia/lymphoma IIB (predicted) \\
\hline 1381350_at & 9.8 & $\mathrm{Al} 317824$ & & Transcribed locus \\
\hline 1387288_at & 9.5 & NM 019218 & Neurod I & neurogenic differentiation I \\
\hline 1369679_a_at & 9.2 & $\overline{\mathrm{AB} 060652}$ & Nfia & nuclear factor I/A \\
\hline 1378776_at & 6.8 & BE097103 & Pou6fl & POU domain, class 6 , transcription factor I \\
\hline 1374625_at & 6.6 & All76616 & Hes6 & hairy and enhancer of split 6 (Drosophila) (predicted) \\
\hline 1394022_at & 6.2 & BEII6009 & $\mathrm{Idb} 4$ & inhibitor of DNA binding 4 \\
\hline 1371570_at & 6.0 & $\mathrm{Al} 406266$ & Scrtl & scratch homolog I, zinc finger protein (predicted) \\
\hline 1380552_at & 6.0 & $\overline{\mathrm{Al} 555855}$ & & Transcribed locus \\
\hline 1374|87_at & 5.9 & $\mathrm{Al} 233361$ & & Transcribed locus \\
\hline 137|202_a_at & 5.9 & $\underline{A B O 12232}$ & Nfib & nuclear factor $\mathrm{I} / \mathrm{B}$ \\
\hline 1383937_at & 5.6 & $\mathrm{~B} 1284495$ & & transcription factor AP-2, gamma \\
\hline 1367946_at & 4.7 & NM 017365 & Pdlim I & PDZ and LIM domain I (elfin) \\
\hline 1379674_at & 4.5 & BEII548I & Cbfa2t3 & core-binding factor, alpha subunit 2;3 (predicted) \\
\hline |37|043_a_at & 3.9 & $\mathrm{BE} 107327$ & Pou3f3 & POU domain, class 3 , transcription factor 3 \\
\hline 1383573_at & 3.9 & BEII7444 & & Serologically defined colon cancer antigen 33 (predicted) \\
\hline 1377206_at & 3.6 & $\mathrm{~B} 1282093$ & LhxI & LIM homeobox protein I \\
\hline 1387349_at & 3.4 & NM 013028 & Shox2 & short stature homeobox 2 \\
\hline 1369765_at & 3.3 & NM 022384 & Ascll & achaete-scute complex homolog-like I (Drosophila) \\
\hline 1388|85_at & 3.2 & All78012 & Rbl & retinoblastoma I \\
\hline 1370946_at & 3.2 & BF420722 & Nfix & nuclear factor $\mathrm{I} / \mathrm{X}$ \\
\hline 1370963_at & 3.2 & AJ131902 & Gas7 & growth arrest specific 7 \\
\hline 1385|73_at & 3.1 & BEII6944 & Ebf3 & early B-cell factor 3 (predicted) \\
\hline 1370694_at & 3.1 & $\mathrm{AB} 020967$ & Trib3 & tribbles homolog 3 (Drosophila) \\
\hline 1378859_at & 3.0 & $\mathrm{Al058446}$ & & aristaless 3 \\
\hline 1372299_at & 3.0 & $\mathrm{~A} 1013919$ & Cdknlc & cyclin-dependent kinase inhibitor IC (P57) \\
\hline 1371024_at & 3.0 & AW527515 & Cutll & cut-like I (Drosophila) \\
\hline 1398548_at & 2.9 & $\underline{B F 389746}$ & Nr6al & Nuclear receptor subfamily 6 , group A, member I \\
\hline 1371034_at & 2.9 & $\overline{\mathrm{BF} 396189}$ & Onecutl & one cut domain, family member I \\
\hline 1387|22_at & 2.9 & NM 012760 & Plagll & pleiomorphic adenoma gene-like I \\
\hline 1378487_at & 2.7 & BF403191 & Ep300 & EIA binding protein $\mathrm{p} 300$ \\
\hline 1384840_at & 2.7 & AA924754 & Prrxl & Paired related homeobox I \\
\hline |395|6|_at & 2.7 & $\underline{A W 531604}$ & Mytl & myelin transcription factor I (predicted) \\
\hline 1387200_at & 2.6 & NM 021770 & OligI & oligodendrocyte transcription factor I \\
\hline 1392089_at & 2.6 & AW435314 & $\mathrm{Hcfc2}$ & host cell factor C2 (predicted) \\
\hline 1392477_at & 2.6 & $\mathrm{Al059914}$ & Etvl & ets variant gene I (predicted) \\
\hline |38870I_at & 2.5 & Al555336 & & mixed lineage-leukemia translocation to 6 homolog \\
\hline 1372274_at & 2.5 & $\mathrm{~A} 1009727$ & & mixed-lineage leukemia 5 (trithorax homolog) \\
\hline | 383247_a_at & 2.5 & $\mathrm{~B} 1291029$ & Mybbpla & MYB binding protein (PI60) la \\
\hline 1387274_at & 2.5 & NM 012943 & DIx5 & distal-less homeobox 5 \\
\hline 1372093_at & 2.5 & Al409308 & Mxil & Max interacting protein I \\
\hline 1383736_at & 2.4 & All 45457 & Elavl2 & ELAV (embryonic lethal, abnormal vision) \\
\hline 1397779_at & 2.4 & $\overline{\mathrm{BF} 562254}$ & & Chromodomain helicase DNA binding protein 2 (predicted) \\
\hline 1383166_at & 2.4 & BEI00595 & & Transcribed locus \\
\hline 1380363_at & 2.4 & BF420490 & KIf7 & Kruppel-like factor 7 (ubiquitous) (predicted) \\
\hline 1386080_at & 2.4 & $\overline{\mathrm{BE} 107815}$ & Heyl & Hairy/enhancer-of-split related with YRPW motif I \\
\hline 1385227_at & 2.4 & $\mathrm{BF} 398245$ & Trpsl & trichorhinophalangeal syndrome I (predicted) \\
\hline 1385215_at & 2.3 & $\overline{\mathrm{BF} 388857}$ & Cbfa2tl & core-binding factor, runt domain, alpha subunit 2 \\
\hline 1372319_at & 2.3 & BF2828II & & Transcribed locus, strongly similar to XP_2308II.3 \\
\hline 1392676_at & 2.2 & Al548984 & & myocardial ischemic preconditioning upregulated I \\
\hline 1370535_at & 2.2 & $\underline{\mathrm{U} 48809}$ & Mytll & myelin transcription factor I-like \\
\hline 1397734_at & 2.2 & AW524780 & & Sp3 transcription factor \\
\hline |36884|_at & 2.1 & NM 053369 & Tcf4 & transcription factor 4 \\
\hline 1373256_at & 2.1 & BM391119 & Chd3 & Chromodomain helicase DNA binding protein 3 (predicted) \\
\hline 1389994_at & 2.1 & BEI04268 & Soxll & SRY-box containing gene II \\
\hline 138|489_at & 2.1 & $\overline{\mathrm{BE} I \mid 4007}$ & Sox6 & SRY-box containing gene 6 (predicted) \\
\hline
\end{tabular}


determine whether specific miRNAs may be contributing to gene regulation during this developmental period. Key to our approach was purifying neuronal progenitor cell populations at the earliest stages of cortical neurogenesis using FACS and obtaining the transcriptome and miRNAome profiles of these cells. This study extends our previous work on lineage-negative NSCs [19], to now include the positively selected neuronal progenitor progeny of NSCs. In the current study, we included two additional lineage-restricted markers (TnTx and A2B5) to ChTx and Jones used in our previous neural cell identification strategy. TnTx is a pan-neuronal surface marker that labels early neuronal progenitors and post-mitotic neurons. A2B5 is a neuroglial progenitor marker that is retained by early neuronal populations specifically derived from this progenitor (see reference [20]). TnTx and A2B5 have largely overlapping expressions with ChTx and Jones, respectively. All four markers were used in this study to more stringently discriminate and isolate by FACS the TnTx+/ChTx+ NPs derived from A2B5-Jones-precursors, which predominate at the onset of cortical neurogenesis, and to minimize contamination from $\mathrm{TnTx}+/ \mathrm{ChTx}+\mathrm{NPs}$ derived from A2B5+Jones+ progenitors that increasingly emerge during later cortical development. Four independent biological replicates were collected for each timepoint with very good reproducibility. Using this "-omics" strategy, we identified two major classes of dynamically regulated mRNAs and miRNAs between embryonic days E11 and E13, a developmental period that spans the onset of rat cortical neurogenesis.

The GO analysis focused our attention on TFs since mRNAs encoding TFs make up the largest class of genes being up-regulated and the second largest class of genes being down-regulated in the dataset. The high number of TFs up-regulated (60 TFs listed in Table 2) was not surprising considering the likely heterogeneity of neuronal subpopulations to emerge by E13 in the telencephalon. At this stage of development, the telencephalon includes: pioneer neurons, Cajal-Retzius neurons, tangentially migrating GABAergic neurons, and some of the first pyramidal neurons $[2,3]$. Likewise, a large number of TFs (83 listed in additional file 2) were down-regulated between E11 and E13. We speculate that the diversity of TFs in the proliferating E11 neuronal progenitor population may arise from multiple TF expression domains along the rostral-caudal axis of the telencephalon. Summary of all the TFs identified here is beyond the scope of this paper, but up-regulated TFs include proteins with previously defined roles in cortical development. For example, the transcription factor Bcl11b is up-regulated 28.6fold in E13 ENPs and is required for proper axonal projection of corticospinal motor neurons [22]. Dlx1 is up-regulated 30.2-fold in E13 ENPs, and in transgenic mice lacking both Dlx1 and Dlx2, GABAergic interneurons in the forebrain fail to migrate [23]. Klf7 is up-regulated 2.4fold in E13 ENPs, and Klf7 null mice show a reduction in cortical thickness [24]. Overall, these results suggest that the novel TFs identified in this study may also be important in regulating cortical development.

miRNAs have proven to be important in a number of different developmental processes including the regulation of neuronal progenitors progressing into differentiated neurons $[15,16]$. In this study, we contribute to the catalog of miRNAs that are expressed during mammalian brain development. The developmental time course of this experiment allowed the identification of differentially-expressed miRNAs during the earliest stages of cortical neurogenesis between E11 and E13.

The expression profiles of both mRNAs and miRNAs allowed us to ask whether there was a correlation between the expression levels of miRNAs and the predicted mRNA targets of each miRNA. We found that $33 \%$ of the miRNAs that were down-regulated and $64 \%$ of the miRNAs that were up-regulated were indeed negatively correlated with the expression pattern of their predicted target mRNAs. Notably, we found miR-222, miR-291-3p, miR-183, miR363-3p, miR-92, miR-19a and miR-145 as down-regulated miRNAs between E11 and E13 and whose expression was negatively correlated with the expression of their predicted targets. No clear roles for these miRNAs have been established yet. Of interest on the list of miRNAs that were down-regulated between $\mathrm{E} 11$ and $\mathrm{E} 13$ was the miR290 family, which is expressed by embryonic stem (ES) cells $[25,26]$. The number of mRNAs down-regulated between E11 and E13 encoding proteins involved in cell cycle regulation (see additional file 3 ), and the expression of miR-290, miR-291-3p, and miR-292-3p, are interpreted as an indication of the proliferative phenotype of the E11 ENPs, which likely contain cells that are only a cell division away from neural stem cells. We also found up-regulated miRNAs between E11 and E13 belonging to a well-characterized category of brain-enriched miRNAs. These include miR-7, miR-9, miR-124a, miR-125a/b, miR-181b/c and miR-99a/b. Interestingly, miR-9, miR124a, miR-99a/b and miR-181b/c up-regulation during early cortical neurogenesis was negatively correlated with the expression level of their predicted targets, consistent with reports that have found a negative expression correlation between tissue-enriched miRNAs and their putative targets $[17,18]$. Some brain-enriched miRNAs have also been reported to be co-expressed with their target genes [27]. The complexity of the mammalian nervous system may give rise to these disparate findings, which could be caused by differences in developmental time points examined or differences in cell types used in the analysis. 

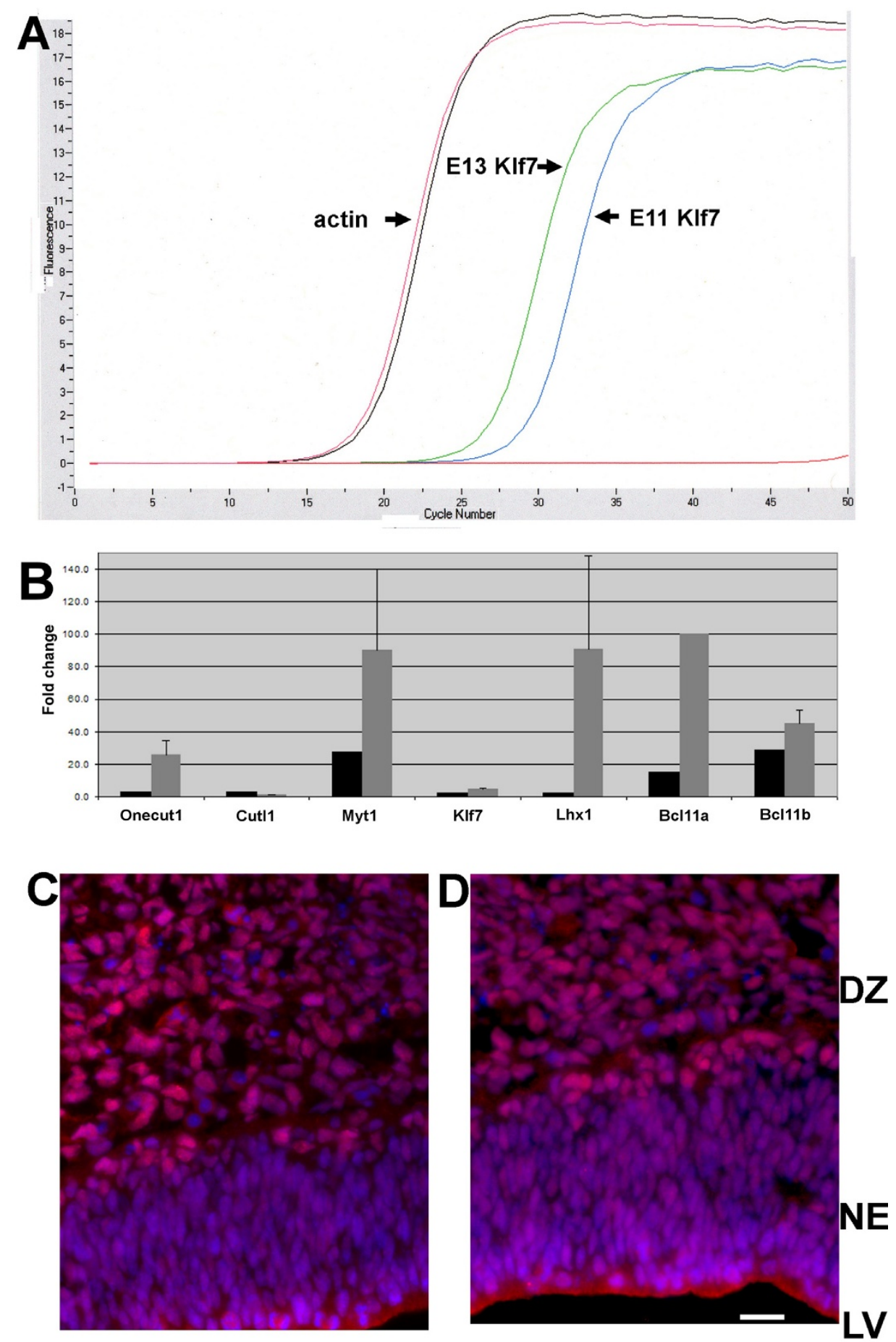

\section{Figure 4}

Differentially expressed mRNAs detected by microarrays were validated with qRT-PCR and immunohistochemistry. A. The cycle threshold of KIf7 is shifted to the left in EI 3 ENPs confirming an increase in KIf7 mRNA expression level, while the beta-actin mRNA expression level remains nearly constant. B. The fold changes from EII to EI 3 for seven transcription factors identified by microarrays (black bars) and qRT-PCR (grey bars) are plotted. C, D. Cutll protein (red fluorescence) is expressed at EI3 in the differentiating zone (DZ) of the ventral (C) and dorsal (D) telencephalon. The blue fluorescence depicts nuclear counterstain with DAPI. The lateral ventricle (LV) is at bottom of the figure. NE = neuroepithelium. Scale bar $=20$ microns. 


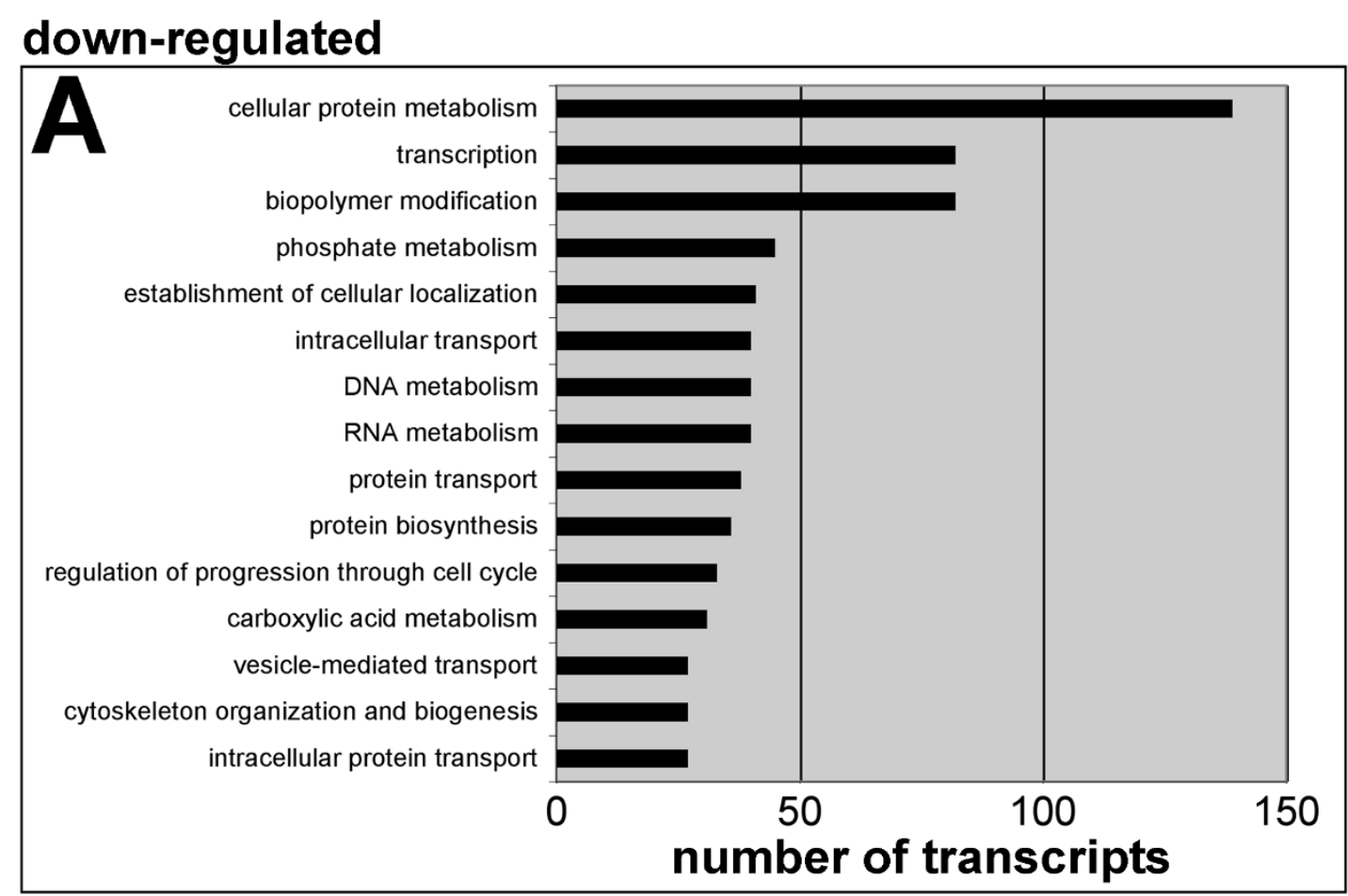

\section{up-regulated}

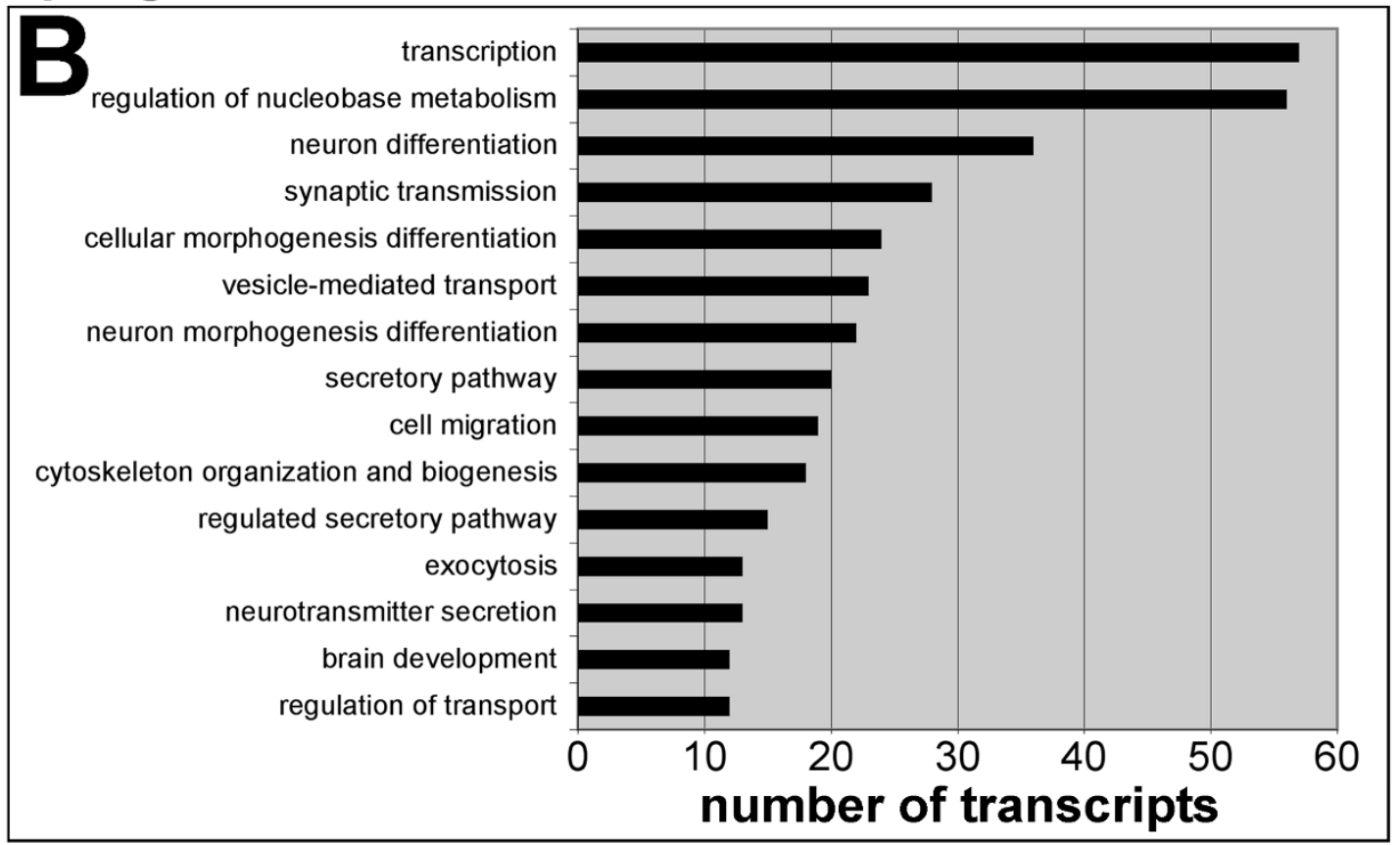

\section{Figure 5}

Gene ontology (GO) analysis of differentially regulated transcripts. The mRNAs encoding transcription factors make up the second largest class of mRNAs being down-regulated $(\mathbf{A})$ and the largest class of mRNAs being up-regulated (B). Differentially regulated gene lists (see methods) were imported into DAVID for GO analysis. The analysis was confined to the biological process category (GO level 5). The $15 \mathrm{GO}$ categories with the highest number of mRNAs annotated were included with the number of mRNAs in each category graphed on the $x$-axis. 
Table 3: Gene ontology analysis identifies 35 transcripts up-regulated in EI 3 neuronal progenitors annotated with the GO term: neuron differentiation.

\begin{tabular}{|c|c|c|c|c|}
\hline Affymetrix ID & Fold $\Delta$ & GenBank & Gene & Gene Description \\
\hline 1384944_at & 43.3 & BEII6855 & Bcll lb & B-cell leukemia/lymphoma IIB (predicted) \\
\hline |37004|_at & 11.7 & NM 053440 & Stmn2 & stathmin-like 2 \\
\hline 1378776_at & 6.8 & BE097103 & Pou6fl & POU domain, class 6 , transcription factor I \\
\hline |3684||Ia_at & 4.6 & $\underline{X 74211}$ & Mtap2 & microtubule-associated protein 2 \\
\hline 1391019_at & 3.4 & BF285698 & Slitrk I & SLIT and NTRK-like family, member I (predicted) \\
\hline 1377308_a_at & 3.4 & $\overline{B F 398408}$ & & Neurotrophic tyrosine kinase, receptor, type 3 \\
\hline | 368097_a_at & 3.4 & NM 053865 & Rtn I & reticulon I \\
\hline 1369765_at & 3.3 & NM 022384 & Ascll & achaete-scute complex homolog-like I (Drosophila) \\
\hline 1371618_s_at & 3.3 & $\mathrm{Al} 229029$ & Tubb3 & tubulin, beta 3 \\
\hline 1370043_at & 3.3 & NM 031753 & Alcam & activated leukocyte cell adhesion molecule \\
\hline 1372299_at & 3.0 & $\mathrm{Al} 013919$ & Cdknlc & cyclin-dependent kinase inhibitor IC (P57) \\
\hline |36826|_at & 2.7 & NM 053817 & Nrxn3 & neurexin 3; hypothetical gene supported by NM_0538I7 \\
\hline 1395357_at & 2.7 & BG672052 & Maplb & microtubule-associated protein Ib \\
\hline |39067|_at & 2.7 & $\mathrm{Al} 044666$ & lgfir & Insulin-like growth factor I receptor \\
\hline 1373683_at & 2.7 & $\mathrm{~A} 1230396$ & Fyn & fyn proto-oncogene \\
\hline 1387200_at & 2.6 & NM 021770 & OligI & oligodendrocyte transcription factor I \\
\hline 1392477_at & 2.6 & $\mathrm{~A} 1059914$ & Etvl & ets variant gene I (predicted) \\
\hline |3679|8_at & 2.5 & NM_031066 & Fezl & fasciculation and elongation protein zeta I (zygin I) \\
\hline 1387274_at & 2.5 & NM 012943 & Dlx5 & distal-less homeobox 5 \\
\hline 13880|5_at & 2.4 & $\underline{\cup 04998}$ & Ptprzl & protein tyrosine phosphatase, receptor-type, Z polypept. I \\
\hline 1379693_at & 2.4 & $\mathrm{Al} 409154$ & Robo2 & Roundabout 2 (Drosophila) \\
\hline 1395986_at & 2.3 & $\overline{\mathrm{BF} 391439}$ & Slit2 & slit homolog 2 (Drosophila) \\
\hline 13884 |9_at & 2.3 & AW915005 & & CDK5 regulatory subunit associated protein 2 \\
\hline 1369213_at & 2.3 & NM 017345 & & neural cell adhesion molecule LI \\
\hline 1379526_at & 2.3 & $\overline{\text { BG374506 }}$ & Mbp & Myelin basic protein \\
\hline 1387424_at & 2.2 & NM 012884 & Cntn2 & contactin 2 \\
\hline 1370|24_at & 2.2 & NM 053968 & Mt3 & metallothionein 3 \\
\hline |368|48_at & 2.2 & NM 012610 & Ngfr & nerve growth factor receptor (TNFR superfamily, mem 16) \\
\hline 1381215_at & 2.2 & AA900967 & & PREDICTED: similar to Numbl protein [Rattus norvegicus] \\
\hline 1368472_at & 2.1 & NM 031320 & Celsr3 & cadherin EGF LAG seven-pass G-type receptor 3 \\
\hline 1396|50_at & 2.1 & AW917275 & CldnI & claudin I \\
\hline 1374403_at & 2.1 & BF4I2072 & Efnbl & ephrin BI \\
\hline 1382205_at & 2.1 & AW527509 & & Transcribed locus \\
\hline 1386948_at & 2.0 & NM 012987 & Nes & Nestin \\
\hline |368879_a_at & 2.0 & $\mathrm{AF} 413212$ & Gnao & guanine nucleotide binding protein, alpha $\circ$ \\
\hline
\end{tabular}

Currently, mammalian miRNAs are not thought to be a primary gene regulatory mechanism. Rather, mammalian miRNAs are thought to act more by fine-tuning the changes of gene expression that are largely under transcriptional control [28]. We speculate that the negative correlation between miRNAs expression and the predicted target mRNA expression identified in this study may be an indication that these tissue enriched miRNAs help to finetune transcriptional control by post-transcriptionally modulating the levels of their target mRNAs. Experimental validation of miRNA-target mRNA interaction is required to confirm this hypothesis.

The mechanisms by which miRNAs degrade their targets are not well characterized. There may be cooperation between translation inhibition and mRNA degradation involving deadenylase and decapping complexes [29]. In a rare example in which miRNA directs slicer-mediated cleavage of the target, a high degree of complementarity exists between the miRNA and its binding site in the 3'UTR [30]. Since mammalian miRNAs interact with their targets using less extensive base pairing in the binding site, our data support the fine-tuning model for tissueenriched miRNAs and leave open the possibility that miRNAs employ mRNA degradation more often than currently recognized, through yet uncharacterized mechanisms.

The negative correlation between miRNAs and predicted target mRNAs expression identified in this study supports the hypothesis that miRNAs may be modulating the expression of genes required during cortical neurogenesis. Further support for this hypothesis was provided by the GO analysis of the differentially regulated mRNAs that were classified as predicted targets of miRNAs. Notably, mRNAs that were down-regulated and predicted to be tar- 


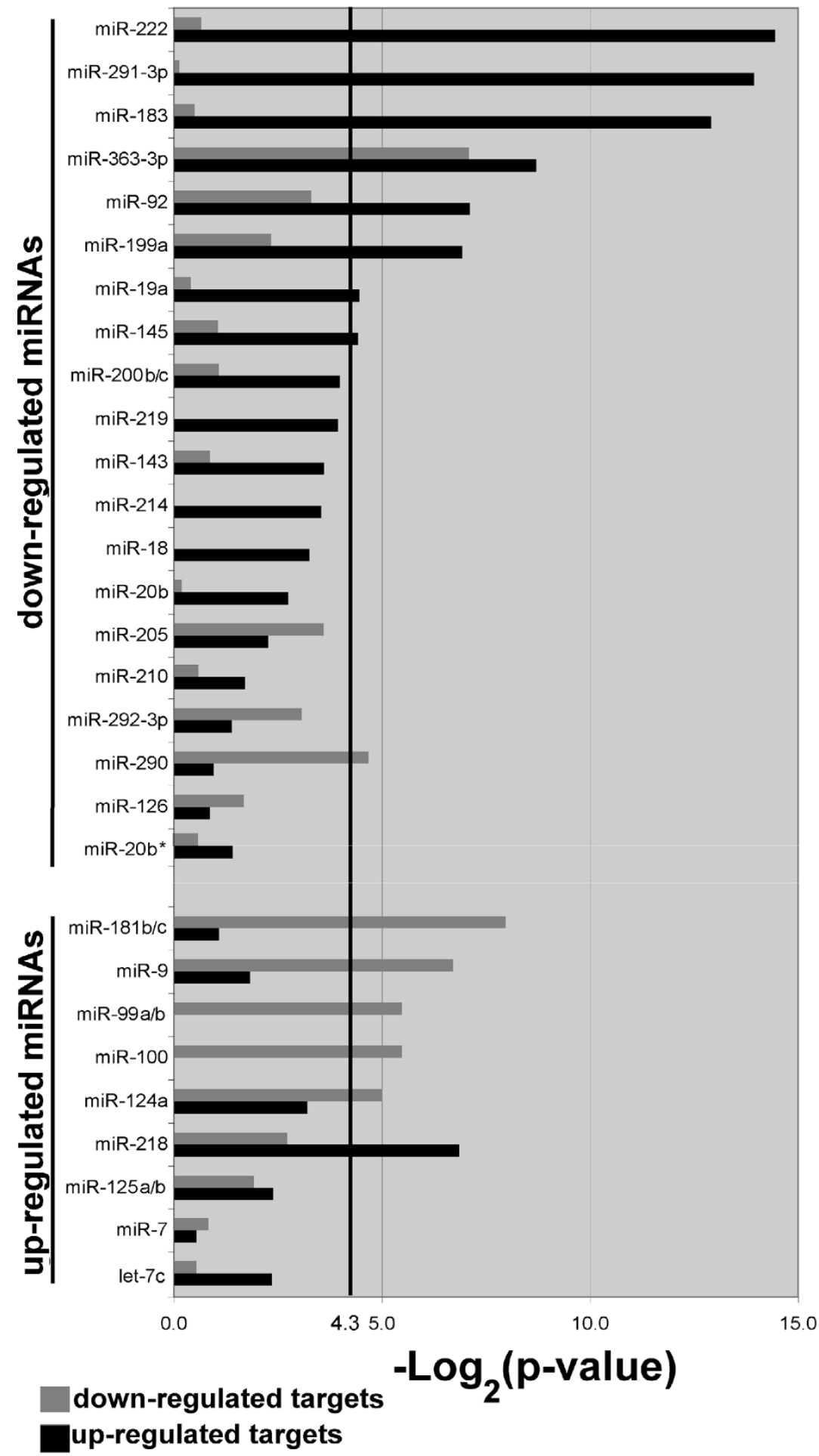

Figure 6

miRNA expression is negatively correlated with target mRNA expression. Predicted target mRNAs for each miRNA were identified using TargetScan 4.0 and compared with the lists of experimentally-determined, differentially-regulated mRNAs. A two-tailed Fisher's Exact Test was used to determine whether there were more predicted target mRNAs with differential expression than would be expected by chance $(p<0.05$, above heavy black line at 4.3$)$. The negative log of the $p$-value is plotted on the $x$-axis for both down-regulated mRNAs (grey) and up-regulated mRNAs (black). 


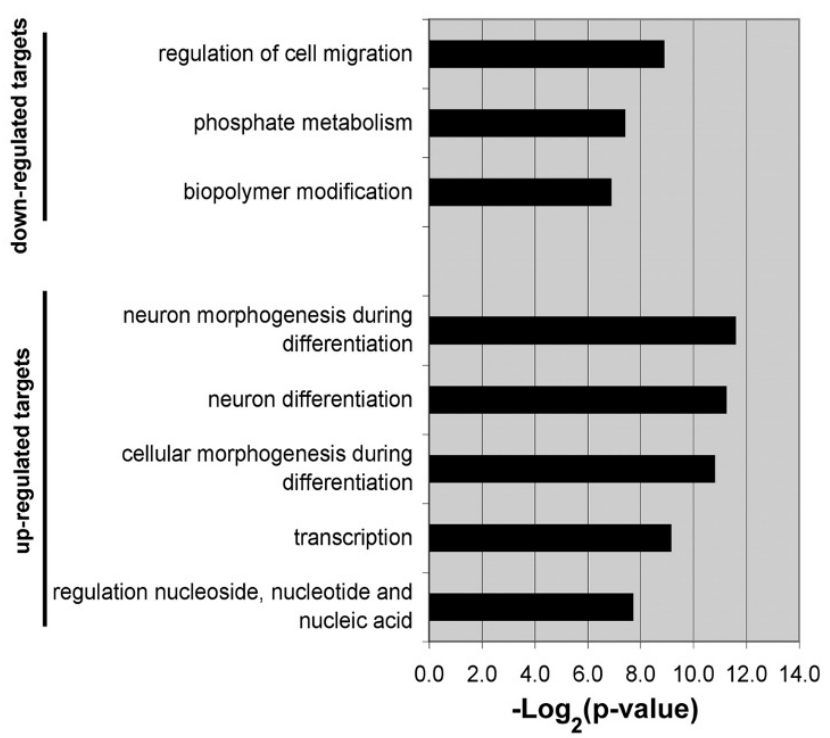

\section{Figure 7}

GO analysis identifies potential mRNA functional categories regulated by miRNAs during neuron differentiation. GO analysis was performed on mRNAs predicted to be targets of miRNAs, which were negatively correlated with target mRNA expression. The GO analysis was confined to the biological process category (GO level 5). Only categories with a p-value greater that 0.05 are included. The negative log of the $p$-value is plotted on the $x$-axis.

geted by up-regulated miRNAs were enriched in mRNAs encoding proteins involved with cell migration (Figure 7). One of these mRNAs was Cxcr4, which is down-regulated 2.4-fold and is predicted to be targeted by miR-9, which was up-regulated over a hundred fold. Since CXCR4 is required for radial and tangential migration in the developing cortex [31], we speculate that the up-regulated miRNAs identified in this study may help dampen the expression of genes no longer required as neuronal differentiation progresses, as has been previously suggested $[10,32]$.

The mRNA encoding the cyclin dependent kinase inhibitor 1c $(C d k n 1 c)$ was up-regulated 3-fold in E13 ENPs and is predicted to be targeted by three miRNAs that were down-regulated: miR-92, miR-222, and miR-363-3p. CDKN1C has been reported to negatively regulate proliferation of cortical progenitors by inhibiting the cell cycle progression machinery [33]. It is thus tempting to hypothesize that the down-regulated miRNAs identified in this study may act as progenitor maintenance factors helping to prevent aberrant or leaky expression of genes that would interfere with the proper timing of cortical neurogenesis. Additional support for this hypothesis was provided by the miRNA-TF mRNA network analysis in Figure
8. We found four down-regulated miRNAs (miR-92, miR183, miR-222 and miR-291-3p) that were predicted to target multiple TFs, which were up-regulated in E13 ENPs. The importance of keeping pro-neural TFs silenced in neuronal progenitors may explain TF targeting by multiple miRNAs. These findings are consistent with a role for miRNAs helping to regulate the transition from the proliferative and migratory phenotype of neuronal progenitors into differentiating neurons. Confirmation of the role of miRNAs in the regulation of neurogenesis awaits functional studies using loss and gain of function experiments.

There were differentially regulated miRNAs identified in this study that did not have a negative correlation, and there were two miRNAs (miR-290, miR-218) that had a significant positive correlation with predicted target mRNAs. The lack of negative correlation could be caused by inaccuracies in miRNA target prediction or by a translational inhibition mechanism rather than RNA degradation, which would prevent detection with mRNA microarrays. The detection of miRNAs with a positive correlation between the miRNA and target mRNA (either both down-regulated or both being up-regulated) suggests some alternative indirect mechanisms or a positive regulatory role for miRNAs, as has been reported for some genes involved in cell cycle regulation [34].

\section{Conclusion}

Understanding the molecular mechanisms that regulate cortical neurogenesis will require the identification of genes with the correct spatial and temporal expression patterns. In this study, we report the mRNA and miRNA expression profiles of the first neuronal progenitors in the developing telencephalon, and provide a catalog of TFs likely to play a role in telencephalon development. In addition, we show that the expression of many dynamically regulated miRNAs are negatively correlated with the expression of their predicted target mRNAs. The complexity of cortical development may require additional levels of gene regulation, and the miRNAs identified in this study are well positioned to regulate gene expression during the transition from neuronal progenitors into differentiated neurons.

\section{Methods \\ Cell preparation and FACS}

The animals used in this study were handled in accordance with an animal protocol approved by the National Institutes of Health IACUC. Telencephalic dissociates were prepared from time-pregnant Sprague-Dawley rats (Taconic, Hudson, NY), as previously described [35]. The age of embryos at each time point was confirmed using crown-rump length. Briefly, the whole telencephalon was microdissected and the tissue was dissociated using gentle trituration in papain. The dissociated cells were purified 


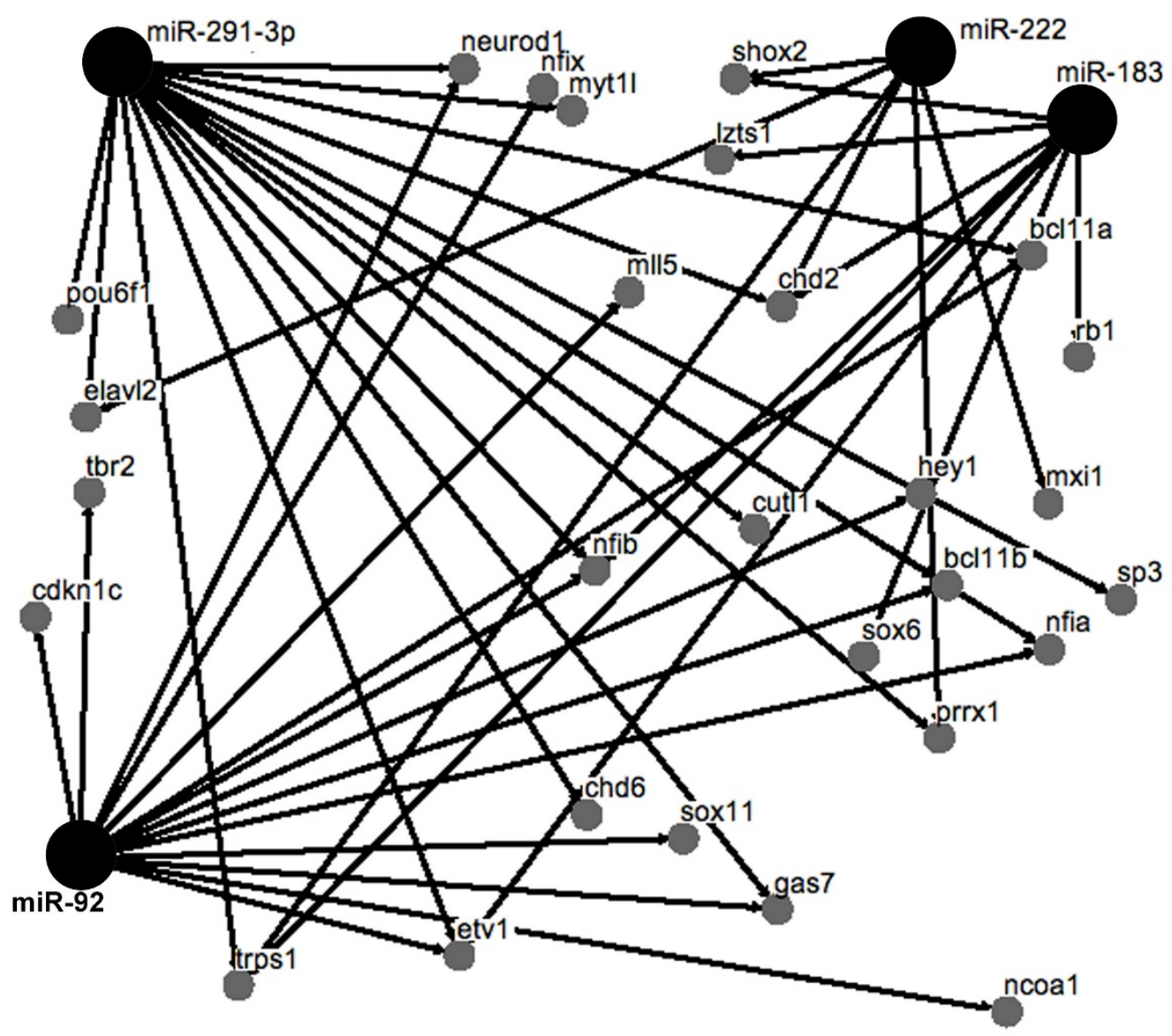

Figure 8

Network analysis identifies miRNAs that are predicted to target multiple transcription factors. The small grey circles identify TFs that were up-regulated in neuronal progenitors between EII and EI3. Larger black circles identify miRNAs that were down-regulated in neuronal progenitors between EII and EI3. The connection lines indicate that a miRNA binding site was identified in the 3' UTR of the transcription factor using TargetScan for miRNA target prediction.

on a Percoll gradient. Telencephalon dissociates were labeled with tetanus-toxin fragment C (TnTx) (Sigma, St. Louis, MO) and biotinylated cholera-toxin B subunit (ChTx) (Roche, Indianapolis IN). TnTx was immunodetected with mouse IgG anti-TnTx and goat anti-mouse IgG conjugated with phycoerythrin (PE) and Cy5 tandem dye (Invitrogen, Carlsbad, CA). ChTx was detected with streptavidin conjugated with PE and Cy5 tandem dye (Invitrogen). The telencephalon dissociates were simultaneously labeled with a combination of mouse IgM antiA2B5 (Chemicon, Temecula, CA) and anti-Jones (CDw60) (Sigma) and detected using goat anti-mouse IgM conjugated with PE (Jackson ImmunoResearch, West Grove, PA). Labeled cell suspensions positive for TnTx and ChTx, but negative for A2B5 and Jones were physically and rapidly sorted into collection tubes containing RNAlater (Ambion, Austin, TX) using a FACSVantageSE flow cytometer (Becton Dickinson, San Jose, CA).

\section{RNA extraction/labeling}

Total RNA was extracted using the RNAeasy micro kit (Qiagen, Valencia, CA). The quality of total RNA was assessed using Agilent's Bioanalyzer microchip (Palo Alto, CA). Briefly, 100 nanograms of total RNA was amplified following Affymetrix's small sample labeling protocol. The protocol uses two rounds of reverse transcription and in vitro transcription with a biotin label being incorporated during the second round of in vitro transcription.

\section{mRNA microarrays}

10 micrograms of biotin-labeled and fragmented cRNA was hybridized to Affymetrix Rat expression 2302.0 microarrays (Affymetrix, Santa Clara, CA). Four independent biological replicates were included in each group. The microarrays were hybridized, washed and scanned according to Affymetrix standard protocols. The raw data was deposited in the Gene Expression Omnibus 
(GEO), [accession number GSE11334], at http:// www.ncbi.nlm.nih.gov/geo/[36]. The quality of the microarray data was assessed by the consistency of the percent present calls, background signal, rawQ and noise. The data was imported into Genespring, (Agilent, Santa Clara, CA) for normalization and data analysis. Robust Multi-Array Analysis (RMA) was used for pre-processing of the raw CEL files, and the data were normalized using a global per chip normalization (normalized to the $50^{\text {th }}$ percentile) and per gene normalization (normalized to the median). A 2-fold difference in normalized expression in combination with a Welch $t$-test was used to identify differentially expressed transcripts. The t-test was performed without an assumption of equal variances, and Benjamini and Hochberg multiple testing correction was used with a false discovery rate of 0.05 .

\section{miRNA microarrays}

Total RNA from FACS-purified E11, E12 and E13 neuronal progenitors was purified using the mirVana miRNA Isolation Kit (Ambion) and used for hybridization with miRNA microarrays (LC Sciences, Houston, TX). Three independent biological replicates were included in each group. The raw data was deposited in the EMBL/EBI ArrayExpress database, [accession number E-MEXP1596], at http://www.ebi.ac.uk/microarray-as/ae/. Slides were scanned using the Axon GenePix 4000B microarray scanner (Axon Instruments, Union City, CA). The microarray images were background subtracted using a local regression method and normalized to the statistical mean of all detectable miRNAs.

\section{mRNA qRT-PCR}

The LightCycler (Roche) was used to perform relative qRTPCR. The cDNA was generated from total RNA isolated from neuronal progenitors purified as described in the cell preparation section. PCR primer pairs specific for seven TFs were designed to span one intron and to yield an approximately 200 bp product size. Melting curves were generated using the LightCycler analysis software to determine whether there were any spurious amplification products, and the PCR products were run on an agarose gel to confirm the presence of a single band. Beta-actin was chosen as a reference gene because it was expressed at equivalent levels in each group according to the microarray data and in preliminary qRT-PCR experiments. Relative qRT-PCR was used to determine the fold difference for the seven TFs [37]. In this method, the PCR efficiency is experimentally determined for each primer pair and calculated as efficiency $=10^{(-1 / \text { slope })}$ with the slope being determined using a dilution series and by the LightCycler analysis software. The difference in cycle threshold between E11 samples and E13 samples was normalized by dividing the difference in the cycle threshold for betaactin in E11 and E13 cDNA samples.

\section{miRNA qRT-PCR}

$150 \mathrm{ng}$ of total RNA from E13 neuronal progenitors was treated with Turbo DNase (Ambion) for 10 minutes at $37^{\circ} \mathrm{C}$. Two independent biological replicates were used in the experiment. First strand synthesis was conducted using the Taqman Reverse Transcription Kit (Applied Biosystems, Foster City, CA). Real-time quantitative PCR was performed using a Taqman Array microRNA Panel v1.0 (Early Access) obtained from Applied Biosystems. PCR was performed on Applied Biosystems 7900HT Fast RealTime PCR Systems using the Taqman 2X Universal PCR Master Mix. The primer sequences are available at http:// appliedbiosystems.com.

\section{Immunohistochemistry}

E13 sections prepared by Histoserve (Gaithersburg, MD) were permeabilized with $0.1 \%$ Triton X-100 for 10 minutes and blocked for 30 minutes with 10\% normal donkey serum and 1\% BSA. Anti-Cutl1 mouse IgG (Abcam, Cambridge, MA) was applied to sections for 2 hours at room temperature. The sections were washed three times for 5 minutes in PBS and detected with a donkey antimouse-IgG Alexa Fluor 594 for 1 hour. Vectashield with DAPI (Vector Lab, Burlingame, CA) was added prior to cover slipping. The sections were observed with an Olympus IX70 microscope and a $40 \times$ objective with a 0.6 numerical aperture. The images were captured with a Cool Snap digital camera (Photometrics, Tucson, AZ).

Neural cell phenotypes emerging at the onset of cortical neurogenesis were identified using a multi-color immunostaining protocol, as previously described [38]. Briefly, $8 \mu \mathrm{m}$ thick sagittal sections of E12 rat telencephalon were immunolabeled for $1 \mathrm{hr}$ at room temperature (RT) using the following mixture of primary antibodies: mouse IgG1 anti-nestin (Millipore, Billerica, MA), mouse IgG2a antiproliferation cell nuclear antigen (PCNA, Millipore), mouse IgG2b anti-tubulin beta III (clone Tuj1, SigmaAldrich) and mouse IgM anti-CDw60 (clone Jones, Sigma-Aldrich). Primary immunoreactions were visualized after a $1 \mathrm{hr}$ incubation at RT with the following mixture of Alexa Fluor (AF)-conjugated goat secondary antibodies: anti-mouse IgG1-Alexa Fluor-AF350, antimouse IgG2a-AF546, anti-mouse IgG2b-AF647 and antimouse IgM-AF488 (Invitrogen, Carlsbad, CA). The sections were imaged using the Axiovert $200 \mathrm{M}$ fluorescence microscope (Carl Zeiss, Thornwood, NY) equipped with standard filter sets (Semrock, Rochester, NY) to detect the above AF fluorophores.

\section{Bioinformatics analysis}

Correlation analysis of the miRNA and mRNA expression profiles was carried out using the lists of differentially expressed miRNAs and mRNAs. The predicted mRNA targets of each of the miRNAs that were differentially regu- 
lated were obtained using TargetScan version 4.0 [39]. The TargetScan identifier was converted to an Affymetrix probe set identifier using Affymetrix's Netaffx web tool [40]. A two-tailed Fisher's Exact Test was conducted for each differentially regulated miRNA to determine whether the number of predicted target mRNAs that were differentially regulated was higher than would be expected by chance $(\mathrm{P}<0.05)$. The Fisher Exact test was conducted for each miRNA using both down-regulated and up-regulated mRNA gene lists. Gene ontology analysis was conducted using DAVID [41]. Network analysis was performed using Osprey [42].

\section{Abbreviations}

CNS: central nervous system; ENP: early neuronal progenitor; LNP: late neuronal progenitor; NGP: neuroglial progenitor; GO: gene ontology; FACS: fluorescence-activated cell sorting; qRT-PCR: quantitative reverse transcription PCR; TF: transcription factor; miRNA: microRNA.

\section{Authors' contributions}

JAN contributed to the study design, mRNA microarray experiments, validation experiments, data analysis and manuscript drafting. PL contributed to the study design, miRNA microarrays, validation experiments, data analysis, manuscript drafting. DM contributed to the study design, flow cytometry, immunohistochemistry, manuscript drafting. JLB contributed to study design and manuscript drafting. LDH contributed to study design and manuscript drafting. All authors read and approved the final manuscript.

\section{Additional material}

\section{Additional file 1}

qRT-PCR validation of miRNA microarray expression data. The expression of 12 miRNAs identified as up-regulated between E11 and E13 were confirmed in E13 neuronal progenitors.

Click here for file

[http://www.biomedcentral.com/content/supplementary/1471-

2202-10-98-S1.doc]

\section{Additional file 2}

$83 \mathrm{mRNAs}$ encoding transcription factors are down-regulated in neuronal progenitors between embryonic day 11 and day 13.

Click here for file

[http://www.biomedcentral.com/content/supplementary/1471-

2202-10-98-S2.doc]

\section{Additional file 3}

Gene ontology analysis identifies 33 transcripts annotated with the GO term: regulation of progression through cell cycle.

Click here for file

[http://www.biomedcentral.com/content/supplementary/14712202-10-98-S3.doc]

\section{Acknowledgements}

We thank Dr. Abdel Elkahloun (NHGRI) and his staff for carrying out the microarray hybridization, washing and scanning. This research was supported by the Intramural Research Program of the NINDS.

\section{References}

I. Guillemot F, Molnar Z, Tarabykin V, Stoykova A: Molecular mechanisms of cortical differentiation. Eur J Neurosci 2006 , 23(4):857-868.

2. Molyneaux BJ, Arlotta P, Menezes JR, Macklis JD: Neuronal subtype specification in the cerebral cortex. Nat Rev Neurosci 2007. 8(6):427-437.

3. Rash BG, Grove EA: Area and layer patterning in the developing cerebral cortex. Curr Opin Neurobiol 2006, I 6(I):25-34.

4. Soria JM, Fairen A: Cellular mosaics in the rat marginal zone define an early neocortical territorialization. Cereb Cortex 2000, I 0(4):400-4I2.

5. Stoykova A, Treichel D, Hallonet M, Gruss P: Pax6 modulates the dorsoventral patterning of the mammalian telencephalon. Neurosci 2000, 20(2I):8042-8050.

6. Xuan S, Baptista CA, Balas G, Tao W, Soares VC, Lai E: Winged helix transcription factor BF-I is essential for the development of the cerebral hemispheres. Neuron 1995, |4(6): | | $4|-| \mid 52$.

7. Abramova N, Charniga C, Goderie SK, Temple S: Stage-specific changes in gene expression in acutely isolated mouse CNS progenitor cells. Dev Biol 2005, 283(2):269-28I.

8. Kudo LC, Karsten SL, Chen J, Levitt P, Geschwind DH: Genetic analysis of anterior posterior expression gradients in the developing mammalian forebrain. Cereb Cortex 2007, I 7(9):2108-21 22.

9. Bartel DP: MicroRNAs: genomics, biogenesis, mechanism, and function. Cell 2004, I I 6(2):28I-297.

10. Bushati N, Cohen SM: microRNA functions. Annu Rev Cell Dev Biol 2007, 23: 175-205.

II. Lee RC, Feinbaum RL, Ambros V: The C. elegans heterochronic gene lin-4 encodes small RNAs with antisense complementarity to lin-14. Cell I993, 75(5):843-854.

12. Thomson JM, Parker J, Perou CM, Hammond SM: A custom microarray platform for analysis of microRNA gene expression. Nat Methods 2004, I(I):47-53.

13. Krichevsky AM, King KS, Donahue CP, Khrapko K, Kosik KS: A microRNA array reveals extensive regulation of microRNAs during brain development. RNA 2003, 9(I 0): | 274- I28I.

14. Miska EA, Alvarez-Saavedra E, Townsend M, Yoshii A, Sestan N, Rakic $P$, Constantine-Paton M, Horvitz HR: Microarray analysis of microRNA expression in the developing mammalian brain. Genome Biol 2004, 5(9):R68.

15. Visvanathan J, Lee S, Lee B, Lee JW, Lee SK: The microRNA miRI 24 antagonizes the anti-neural REST/SCPI pathway during embryonic CNS development. Genes Dev 2007, 2 I (7):744-749.

16. Krichevsky AM, Sonntag KC, Isacson O, Kosik KS: Specific microRNAs modulate embryonic stem cell-derived neurogenesis. Stem Cells 2006, 24(4):857-864.

17. Sood P, Krek A, Zavolan M, Macino G, Rajewsky N: Cell-type-specific signatures of microRNAs on target mRNA expression. Proc Natl Acad Sci USA 2006, I 03(8):2746-275I

18. Farh KK, Grimson A, Jan C, Lewis BP, Johnston WK, Lim LP, Burge $C B$, Bartel DP: The widespread impact of mammalian MicroRNAs on mRNA repression and evolution. Science 2005 , 310(5755): |8|7-|82|.

19. Maric D, Fiorio Pla A, Chang YH, Barker JL: Self-renewing and differentiating properties of cortical neural stem cells are selectively regulated by basic fibroblast growth factor (FGF) signaling via specific FGF receptors. J Neurosci 2007, 27(8): 1836-1852.

20. Maric D, Maric I, Chang YH, Barker JL: Stereotypical physiological properties emerge during early neuronal and glial lineage development in the embryonic rat neocortex. Cereb Cortex 2000, I 0(8):729-747.

21. Gray PA, Fu H, Luo P, Zhao Q, Yu J, Ferrari A, Tenzen T, Yuk DI, Tsung EF, Cai Z, Alberta JA, Cheng LP, Liu Y, Stenman JM, Valerius MT, Billings N, Kim HA, Greenberg ME, McMahon AP, Rowitch DH, Stiles $C D, M a$ Q: Mouse brain organization revealed through 
direct genome-scale TF expression analysis. Science 2004, 306(5705):2255-2257.

22. Arlotta P, Molyneaux BJ, Chen J, Inoue J, Kominami R, Macklis JD: Neuronal subtype-specific genes that control corticospinal motor neuron development in vivo. Neuron 2005, 45(2):207-22I.

23. Anderson SA, Eisenstat DD, Shi L, Rubenstein JL: Interneuron migration from basal forebrain to neocortex: dependence on DIx genes. Science 1997, 278(5337):474-476.

24. Laub F, Lei L, Sumiyoshi H, Kajimura D, Dragomir C, Smaldone S, Puche AC, Petros TJ, Mason C, Parada LF, Ramirez F: Transcription factor KLF7 is important for neuronal morphogenesis in selected regions of the nervous system. Mol Cell Biol 2005, 25(13):5699-57|I.

25. Tang F, Hajkova P, Barton SC, Lao K, Surani MA: MicroRNA expression profiling of single whole embryonic stem cells. Nucleic Acids Res 2006, 34(2):e9.

26. Houbaviy HB, Murray MF, Sharp PA: Embryonic stem cell-specific microRNAs. Dev Cell 2003, 5(2):35I-358.

27. Tsang J, Zhu J, van Oudenaarden A: MicroRNA-mediated feedback and feedforward loops are recurrent network motifs in mammals. Mol Cell 2007, 26(5):753-767.

28. Hornstein E, Mansfield JH, Yekta S, Hu JK, Harfe BD, McManus MT, Baskerville S, Bartel DP, Tabin C): The microRNA miR-196 acts upstream of Hoxb8 and Shh in limb development. Nature 2005, 438(7068):67I-674.

29. Shyu $A B$, Wilkinson MF, van Hoof $A$ : Messenger RNA regulation: to translate or to degrade. Embo J 2008, 27(3):47 I-48I.

30. Yekta S, Shih IH, Bartel DP: MicroRNA-directed cleavage of HOXB8 mRNA. Science 2004, 304(5670):594-596.

31. Liapi A, Pritchett J, Jones O, Fujii N, Parnavelas JG, Nadarajah B: Stromal-derived factor I signalling regulates radial and tangential migration in the developing cerebral cortex. Dev Neurosci 2008, 30(I-3): |17-13|.

32. Bartel DP, Chen CZ: Micromanagers of gene expression: the potentially widespread influence of metazoan microRNAs. Nat Rev Genet 2004, 5(5):396-400.

33. Carey RG, Li B, DiCicco-Bloom E: Pituitary adenylate cyclase activating polypeptide anti-mitogenic signaling in cerebra cortical progenitors is regulated by p57Kip2-dependent CDK2 activity. I Neurosci 2002, 22(5): I583-159|.

34. Vasudevan S, Tong Y, Steitz JA: Switching from repression to activation: microRNAs can up-regulate translation. Science 2007, 3 I 8(5858): | $93 \mid-1934$.

35. Maric D, Maric I, Chang YH, Barker JL: Prospective cell sorting of embryonic rat neural stem cells and neuronal and glial progenitors reveals selective effects of basic fibroblast growth factor and epidermal growth factor on self-renewal and differentiation. J Neurosci 2003, 23(I):240-25I.

36. Barrett T, Suzek TO, Troup DB, Wilhite SE, Ngau WC, Ledoux $P$, Rudnev D, Lash AE, Fujibuchi W, Edgar R: NCBI GEO: mining millions of expression profiles - database and tools. Nucleic Acids Res 2005:D562-566.

37. Pfaffl MW, Horgan GW, Dempfle L: Relative expression software tool (REST) for group-wise comparison and statistical analysis of relative expression results in real-time PCR. Nucleic Acids Res 2002, 30(9):e36.

38. Maric $D$, Barker JL: Fluorescence-based sorting of neural stem cells and progenitors. Curr Protoc Neurosci 2005, Chapter 3(Unit 3): 18.

39. Grimson A, Farh KK, Johnston WK, Garrett-Engele P, Lim LP, Barte DP: MicroRNA targeting specificity in mammals: determinants beyond seed pairing. Mol Cell 2007, 27(I):9I-I05.

40. Liu G, Loraine AE, Shigeta R, Cline M, Cheng J, Valmeekam V, Sun S, Kulp D, Siani-Rose MA: NetAffx: Affymetrix probesets and annotations. Nucleic Acids Res 2003, 3 I (I):82-86.

4I. Dennis G Jr, Sherman BT, Hosack DA, Yang J, Gao W, Lane HC, Lempicki RA: DAVID: Database for Annotation, Visualization, and Integrated Discovery. Genome Biol 2003, 4(5):P3

42. Breitkreutz B], Stark C, Tyers M: Osprey: a network visualization system. Genome Biol 2003, 4(3):R22.
Publish with Bio Med Central and every scientist can read your work free of charge

"BioMed Central will be the most significant development for disseminating the results of biomedical research in our lifetime. "

Sir Paul Nurse, Cancer Research UK

Your research papers will be:

- available free of charge to the entire biomedical community

- peer reviewed and published immediately upon acceptance

- cited in PubMed and archived on PubMed Central

- yours - you keep the copyright
BioMedcentral 